\title{
The Relationship amongst Person-Organization Fit, Safety Consciousness, Safety Climate and Safety Behavior
}

\author{
Ferit Ölçer ${ }^{1} \&$ Cemal Durmuşçelebi ${ }^{2}$ \\ ${ }^{1}$ Mustafa Kemal University, Hatay, Turkey \\ 2 İskenderun Technical University, Hatay, Turkey \\ Correspondence: Cemal Durmuşçelebi, School of Civil Aviation, İskenderun Technical University, İskenderun, \\ Hatay, 31200, Turkey. E-mail: cemal.durmuscelebi@iste.edu.tr
}

Received: April 20, 2018

doi:10.5539/ijbm.v13n9p208

\author{
Accepted: July 11, 2018 \\ Online Published: August 7, 2018 \\ URL: https://doi.org/10.5539/ijbm.v13n9p208
}

\begin{abstract}
Technological advances have reduced accident rates caused by machine-related errors, accidents that have occurred in individual and organizational errors are still continuing. Safety perceptions, attitudes and beliefs of people and their personality traits emerge safe or unsafe behaviors in the work environment. In addition, high congruence of employee characteristics and organizational characteristics supports the creation of a safe working environment. The purposes of this study were to examine the effect of airline employees' person-organization fit, and safety consciousness on safety behavior and investigate the mediation role of safety climate on these effects. The data collected from planning, operations control, flight safety and quality employees of an airline operating in Turkey $(N=178)$. Data were analyzed with the SPSS 22.0 program and factor, correlation and regression analyzes were performed to identify interrelationships with descriptive statistics. Findings show that person-organization fit, and safety consciousness had positive effects on safety climate and safety behavior; safety climate had full mediation role in the effect of person-organization fit on safety behavior; and had a partial mediation role in the effect of safety consciousness on safety behavior.
\end{abstract}

Keywords: Person-organization fit, safety consciousness, safety climate, safety behavior

\section{Introduction}

Occupational safety includes all aspects of physical, mental and social health and safety in a workplace. It is the structure for company's efforts to prevent injuries and hazards related with work environments. All industries have various kinds of safety hazards to its work environments. Occupational safety risks ranges from severe and physical dangers to milder hazards. Hazards in the workplace can harm the company as well as the employees. Safety errors directly impact the company's bottom line and global economy. Findings reveal that worldwide work-related injury and illness result in the loss of $3.9 \%$ of GDP, at an annual cost of roughly $€ 2680$ billion (EU-OSHA, 2017). While it is easy to calculate the economic costs of safety errors to a certain extent, it is not easy to calculate the long-term economic and psychological effects. Accidents resulting from the dead or injured of people cause psychological harm beyond economic costs. Dead or injured person's family, friends, coworkers and other parties suffer from it. Therefore, people want to feel safe. However, possible accidents will greatly reduce employees' work motivation. It may take a long time to return to work after rehabilitation for the employees who see their colleague has been injured or died as a result of an accident. In addition, another problem for the company and employee is that a psychologically negative affected employee will not be able to regain the earlier efficiency.

The physical and psychological costs of accidents have forced regulators to establish rules on occupational health and safety. In order to ensure occupational health and safety, various protection programs are implemented by different companies in different sectors. Companies are obliged to comply with many national and international regulations along with their sector-specific safety practices in its protection program. The efforts of companies to comply with many different regulations can also increase the confusion of employees with the existing workload. Although the safety management system is important in ensuring both the implementation of safety standards and compliance with the regulations, it also contains the inadequacies in preventing the emergence of incidents, accidents and occupational diseases. Safety management system practices, such as detailed workflows, monitoring of activities, auditing, etc. positively affect the company's safety level. However 
it reduces the safety to mechanical processes and causes ignorance of the human aspect of processes. This situation can be seen in the aviation sector as well as in other sectors.

Traditionally, prevention of accidents in the aviation sector includes the control of physical working environment and safety procedures. For example, detailed procedures to ensure the fulfillment of the tasks in the safest manner, the instructions that must be strictly adhered to during the navigation of the aircraft, applications such as use of protective equipment are the physical means of ensuring safety in aviation. While these tools make human behavior mechanized and standardized to ensure safety, they ignore the situations which influence psychology of the employees, such as individual differences and the circumstances in which they are engaged. This study focuses on organizational and individual characteristics that affect the safety behavior (SB) of airline employees, except for physical influences. As organizational characteristics, the effects of safety climate (SC) and person-organizational fit (POF) and personal characteristics of the employee on safety behavior are examined.

SC represents employees' perceptions, attitudes and beliefs about risk and safety (Mearns \& Flin, 1999). Perceptions, attitudes and beliefs shared within the SC shape the SB of employees in the working environment (Clarke, 2010). Similar effects can be seen on SC and SB that are similar to the known effects on organizational outcomes such as job satisfaction and organizational commitment (Kristof-Brown, Zimmerman \& Johnson, 2005). This study mainly focuses on how the employee combines his/her personal characteristics and his/her expectations from the organization and his demands within the perception of SC and develops SB.

\section{Literature Review}

\subsection{Person-Organization Fit}

Kristof (1996) defines POF as the congruence that occurs when individual and organization share the same or similar values; meet each other's needs, or both. The working environment is a system in which complex relationships between people and organizations come together for a mutual goal. People want to work in organizations that are appropriate for their own values and aims, and organizations want to employ people who will help them to achieve their mission and vision. For this reason, inconsistencies can arise between human and organization in terms of value, purpose, expectations and needs. This situation makes POF, the level of the fit, and its effects on the output important (Schneider, 1987). Considering the positive effect of POF on job satisfaction, organizational commitment, organizational citizenship behavior, and labor turnover (Cable \& Judge, 1996; Vilela, Varela Gonzalez, \& Ferrin, 2008), a certain level of congruence has become a necessity in terms of common goals and values. The job choice of the individual and the human resources policy of the organization are also influenced by the POF. Job seekers prefer organizations which share their values, satisfy their expectations and needs considerably. On the other hand, organizations choose knowledgeable and talented employees who they believe will comply with organizational values and norms (Kristof, 1996; Cable \& Judge, 1996).

\subsection{Safety Consciousness}

Consciousness is a personal trait which is defined as socially-determined impulse control that facilitates taskand purpose-focused behaviors. For example, thinking before the action, postponing delight, adapting norms and rules, and planning, organizing, and prioritizing tasks are considered to be the characteristics of the conscious person (John, Naumann \& Soto, 2008). Several studies revealed the effects of some features (Barrick \& Mount, 1991) of the conscious personality structure (rigor, carefulness, organization, and accountability) on organizational commitment (Judge, Bono, Ilies, \& Gerhardt, 2002), job performance (Stewart, 1999), and safety (Sutherland \& Cooper, 1991).

The term of safety consciousness (SCO) refers to the individual's awareness and manner about safety issues and operates both cognitive and behavioral. Cognitively, SCO implies mental awareness of safety in the workplace. Behaviorally, it indicates the awareness of which behaviors will improve operational safety (Koster, Stam, \& Balk, 2011). SCO, in the broadest sense, is based on the awareness of safety threats and are values, attitudes, and beliefs underlying the ability to effectively deal with potentially dangerous situations (Forcier, Walters, Brasher, \& Jones, 2001). In the safety literature, meta-analyzes and other major studies are acknowledged as the obvious indicators to predict SCO, accidents, and safety behaviors (Clarke \& Robertson, 2005; Wallace \& Vodanovich, 2003).

\subsection{Safety Climate}

$\mathrm{SC}$ is common perceptions about safety related actions, practices, policies and procedures that expected, supported and rewarded by organization (Zohar, 2000). Safety is inherent in all production processes. Therefore, a poor sense of SC emerges and settles among the employees if the safety is ignored or not given the necessary 
priority in the organization (Cheyne, Cox, Tomas, \& Oliver, 1998; Flin, Mearns, O'Connor, \& Bryden, 2000). In other words, the SC informs employees about the safety priority, physical or health related risks in the production process (Zohar, 1980). Employees make sense of their environment depending on the actions that their colleagues show in various situations, their supervisor's reactions, and organizational punishment and rewarding given to different practices. For example, whether the employee who acts for short cuts to increase the amount of production is rewarded or punished can be one of the criteria that other employees use to make sense of the environment. In short, employees are trying to perceive and interpret what safety means for the organization. The magnitude of difference between the employee protection program of the organization and its applications in practice determines the level of SC. Therefore, communication channels between the management and the employees gain importance in the communication of the values to the employees. This is because communicative disorders between the management and the employees can result in that the employees misunderstand the fact that the management prioritizes the safety (Zohar, 2013).

As a result of errors in the safety and production system relationship the accident occurs (Zohar, 1980). SC, safe operation related behavior and results (accidents, incidents, near misses, injuries, labor and equipment losses, etc.) due to the organization is associated with many systemic factors. This relationship allows the $\mathrm{SC}$ to be considered as a major indicator of determining the safety level of the organization or workplace (Neal, Griffin, \& Hart, 2000).

\subsection{Safety Behavior}

Safety behavior refers to all the precautionary behaviors such as adherence to safety rules and regulations, safety procedures, participation in safety activities, and the use of personal safety equipment (Clarke, 2006). SB represented a single dimension in the beginning as an act of compliance with rules, policies and procedures related to safety. However, it has evolved into a two-dimensional structure with safety participation behaviors, including the personal safety of employees as well as the safety of the others (Neal et al., 2000). The identification of unsafe behaviors and precursors to explain SB is a prominent issue. Unsafe behaviors are defined as all behaviors that lead to accidents and undesired incidents at workplace. The main reasons for unsafe behaviors are; poor SC, inability to perceive threat level, work pressure, failure in risk perception, and psychological and cognitive errors in the implementation of safety procedures (Seo, 2005). The minimization of the effects of these precursors and transforming unsafe behaviors into safe ones serve an important function in the prevention of accidents (Laurence, 2005).

\section{Research Model and Hypothesis}

In the scope of the research, the research model including POF, SCO, SC, and SB is shown in Figure 1.

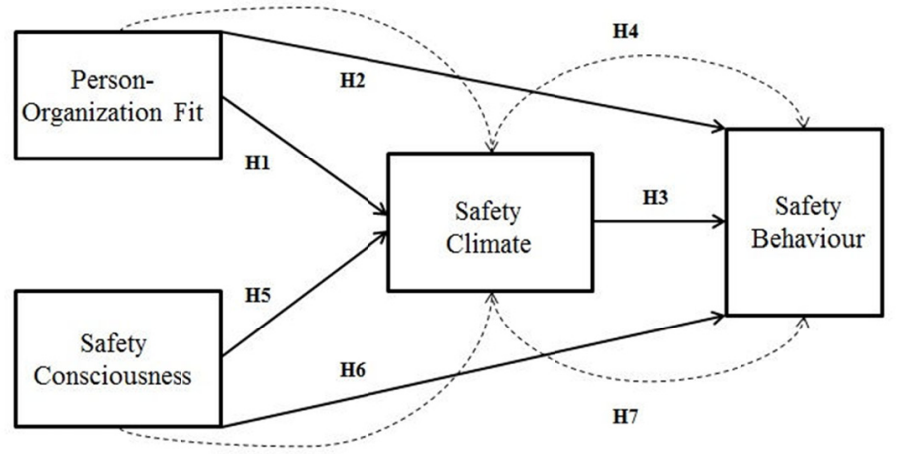

Figure 1. Research model

\subsection{The Relationship between POF, SC and SB.}

POF applies when individuals and organizations have the same or similar values, or mutually meet each other's needs. In risky and dangerous working conditions, it is a need to provide individual safety and health for the individual and to safe the expensive facilities, machinery and vehicles for the organizations. For this reason, the inclusion of safety in both individuals and organizations' mutual expectations and needs may have a positive impact on the level of POF. Therefore, the safety issue can also be seen as one of the basic criteria for POF, particularly for risky and dangerous working environments. This is because if the organization does not share the 
values of and meet the expectations of the employee, there is likely a low level of POF. These remarks and judgments made by employees together with symbolic social interaction in the organization tend to approach and resemble each other over time (Zohar, 2013). Hence, POF has the capacity to lead the perceptions of other employees through symbolic social interaction, as well as on the employee's perception of personal adaptation. This incompatibility can be generally accepted among employees and a poor SC may arise due to common perception on this side. A study (Liao, Lei, Xue, \& Fang, 2013) compared intra-organizational communication and subcontractor's communication, which measured the effect of person-organization fit on safety climate in terms of job requirements and communication performance. In the project development process, high POF in authority contribute efficient job related practices on the division of employees. After project maturity, project managers should pay regard to reducing authority fit to emerge more flexible work environment leading to the statement of employees' thoughts. In this period, low POF in terms of individual authority and higher POF in terms of co-operative duties were revealed positive effect on SC.

The other context related to POF and SC arises at the point of psychological ownership of the work. Employees' positive perception about the fit between their values and the organization's norms and values, lead them to identify themselves with their organizations (Cable \& DeRue, 2002). This aspect of POF is similar to the concept of psychological work ownership developed by Zohar. Zohar (2013) identifies psychological work ownership as one of the SC antecedents. The basic view underlying the SC is the value given by the organization and the management in particular to the safety and health of the employee and the attitude that the employee represents in response to this value. The root of the employee's work psychological ownership in terms of safety (Zohar, 2013) can be associated with the employee's perception of the fit between the safety values and characteristics of the organization and the values and characteristics of the employee. An effect similar to the perceived level of POF on job attitudes and work output (Park, Monnot, Jacob \& Wagner, 2011) may also emerge on the SC and its outputs. Simsek Ilkım and Derin, (2018) found some evidences related with relationship between POF and SC. They argued that perceived positive POF affects SC and interaction of them increase level of job satisfaction. According to the some evidence in POF and SC literature, we propose following hypothesis.

\section{Hypothesis 1: POF has positive effect on SC.}

Theoretical frameworks generally focus on the relationship between job attitudes and POF. However, POF can also have direct or indirect effects on performance. In the literature, POF is known to have significant effects on key organizational outcomes such as job attitudes, performance and labor turnover (Kristof-Brown et al., 2005). However, number of the studies that examine the effects of safety performance outcomes such as accidents, unsafe behaviors, and safety behaviors is insufficient. In this regard, a study (Maierhofer, Griffin, \& Sheehan, 2000) provides evidence of the influence of managers' safety behaviors on employees' safety behaviors, although it has not achieved any conclusions regarding the effects of POF on the employee's SB. But study reached that especially time urgent situations effected safety behaviors negatively. Manager's value of time urgency was related time urgency of employees. Another study related POF and SB are performed by Britton (2014). The study showed safety specific POF is a predictive of safety behaviors. In terms of the nature of the safety specific POF outcome relations, agreement was positively related to safety behaviors and job satisfaction and negatively related to burnout. That is, when psychological SC and safety motivation are congruent, safety behaviors and job satisfaction increase and burnout decreases as the two predictors increase. When there was discrepancy, the direction was such that safety behaviors and organizational commitment were highest when psychological SC was higher than safety motivation. Therefore, studies on the topic show that there may be a meaningful relationship between POF and SB. In our study, the following hypothesis has been developed in order to demonstrate these relationships.

\section{Hypothesis 2: POF has positive effect on $S B$.}

\subsection{The Relationship between $S C$ and $S B$}

As in the case of the factors such as production, efficiency, and productivity, safety is also considered to be a performance outcome for the organization (Zohar, 1980). Criteria for measuring safety performance are based on two criteria: numerical data of accidents, crashes, incidents and near misses, or assessment of safe and unsafe behaviors (Cooper \& Philips, 2004). More positive job attitudes emerge, and a psychological agreement realizes between the organization and the employee, if the employees' safety perceptions about work environments are positive (Dawis \& Lofquist, 1984). Moreover, the management's commitment to safety and the minimization of the risks at work pave the way for the development of positive attitudes and behaviors by the employees (Coyle-Shapiro \& Kessler, 2000). Positive SC encourages employees to engage in SB together with organizational rewards, while negative SC encourages unsafe behaviors (Oliver, Cheyne, Tomas, \& Cox, 2002; 
Tomas, Melia, \& Oliver, 1999). At the same time, it provides the sustainability of SB, including positive SC, safety participation and compliance (Cheyne, Cox, Oliver, \& Tomas, 1998). Negative safety climate perception leads up to the breaches of policy and procedural violations of safety and facilitates the emergence of accidents. Violations of safety penetrate the entire system, making the system more vulnerable to accidents. Violations are divided into intended and unintended violations and follow different paths. While intended violations are related to the employee's safety motivation and safety attitude, unintended violations are related to the employee's knowledge of the rules and procedures (Fogarty \& Buikstra, 2008). In unintended violations, risk taking is not generally conscious, but rather results from the search for a shortcut to make work more efficient, faster or to meet the expectations (Reason, 1998). Effect of SC on SB has the common consensus in the safety literature. Therefore we developed following hypothesis.

\section{Hypothesis 3: SC has positive effect on $S B$.}

\subsection{The Mediating Role of SC in the Relationship between POF and SB}

Maierhofer et al. (2000) argued that the safety behaviors of managers influence the safety behaviors of employees, even though the compliance of safety values of employees and managers has not shown a direct effect on safety behaviors. Therefore, even if employees do not share the values of the managers related to safety, they consider the manager's behavior in safety matters. Thus, the place of safety within the ongoing organizational activities is determined by the actions of the management. Because the management decides at which position the safety will be against the factors affecting the direct costs such as the amount of production, speed, efficiency in the organization. Therefore, employees develop attitudes by evaluating the management's point of view on safety. If management has poor attitudes about safety, employees also develop poor attitudes and the result is a poor SC within the organization (Zohar, 2013). POF plays a role in the formation of organizational culture and climate. That's because the organization attracts job seekers who share its values and employ those who can meet organizational needs. Moreover, employees may leave the organization if their mutual demands do not match. Hence, a more homogeneous group dominates the organization in terms of value, need and expectation (Schneider, 1987). For this reason, it is likely that this homogeneous group, affecting the general SC level of the organization. Thus, we propose that the effect of the employee is indirect and mediated by SC. Based on the theoretical framework discussed above; this study was developed following hypothesis.

Hypothesis 4: The safety climate mediates the relationship between person-organization fit and safety behavior.

\subsection{The Relationship between SCO and SC}

$\mathrm{SC}$ represents the perception of employees regarding the safety of the organizational environment, while SCO refers to personal safety perceptions of employees.SC and SCO affect SC when evaluated alone (Wallace \& Chen, 2006; Clarke \& Robertson, 2005; Wallace \& Vodanovich, 2003; Clarke, 2010; Zohar, 2000). The effects of SCO and SC on the working life are of importance both for personal safety and for the formation of SC. In the recruitment process of the organizations aiming to create a strong SC, candidates are assessed according to personality traits such as consciousness (Meyer, Dalal, \& Bonaccio, 2009). Because the effects of socialization process on personality characteristics are limited. Personality is shaped by the individual's hereditary characteristics and environmental effects. If a candidate to be recruited has a personality which is defined as prone to accidents and has low SCO, this situation limits the success of organizational socialization processes. However, in theories of POF, it is expressed that organization culture and organizational climate are formed by the dominant culture in organization and that this dominant culture constitutes a homogeneous structure among the employees. Therefore, the dominant culture formed by the homogeneous group related to the safety also defines the safety climate (Meyer et al., 2009; Schneider, 1987; Barrick \& Mount, 1991).

Safety-based transformation leadership and the SCO, which states employees' awareness of safety issues, have a meaningful relationship with the SC, and that the SC perceptions are positively or negatively affected by this level of relationship (Barling, Loughlin, \& Kelloway, 2002). This relationship is facilitating or making it difficult for accidents and incidents to occur. In another study on SCO and SC, Lee and Dalal (2014) examined the effects of the level of safety climate in relation to consciousness and safety behaviors and found a positive relationship between SC and SCO at the personal and organizational level. It is also figured in the study that the effect of intra-organizational conditions also contributed to the emergence of this relationship. Considering the researches on the subject, it provides a supporting framework for the following hypothesis which argues that SCO positively affects the SC.

Hypothesis 5: The safety consciousness has positive effect on safety climate. 


\subsection{The Mediating Role of SC in the Relationship between SCO and SB}

Consciousness is considered the best and consistent personality trait to anticipate overall work performance (Barrick \& Mount, 1991). In the safety literature, meta-analyzes and other major studies have also reported consciousness as a stronger indicator to anticipate the accidents and safety behaviors than other personality traits (Clarke \& Robertson, 2005; Wallace \& Vodanovich, 2003). From a theoretical point of view, SCO is likely to affect SB. The conscious employee appears to have features such as self-control, procedure-orientation, hard-working, a logical approach in decision-making, and making fewer mistakes (Barrick \& Mount, 2009; Kaplan \& Tetrick, 2011). Based on these characteristics, it is assumed that employees with conscious personality have a high-level SCO on the issues related to safety, and that this situation reflects their behavior during work (Barling et al., 2002). Studies on SCO and SB, have reached some conclusions which support this assumption.

\section{Hypothesis 6: The safety consciousness has positive effect on safety behavior.}

Positive safety climate emerges dependent on employees' positive perceptions according to safety actions of management in workplace. Actions and perceptions increase organizational commitment and satisfaction and impact behaviors. To assess the impact of safety climate on workplace outcomes, measurement of relationship between employee perceptions and individual behaviors are necessary. Theoretical perspectives present relationship between employees' perceptions of work environment and attitudes and behaviors. Safety consciousness is conceptually different from safety climate perceptions. Whereas the safety climate represents all employees' safety perceptions in work environment, the safety consciousness represents individual safety perceptions. Safety consciousness is also related cognitive and behavioral. Wallace and Vodanovich (2003) argued that the level of consciousness of the employee on the safety level affects the safety performance and cognitive error has a mediator role in this effect and the effect of cognitive error and safety consciousness level on safety behaviors shows a linear relationship with accidents. Also, cognitive ability moderates relationship between consciousness and safety behavior. (Postlethwaite, Robbins, Rickerson, \& McKinniss, 2009). Employees with high level SCO are more successful in demonstrating compliance with safety procedures in workplace (Inness, Turner, Barling and Stride (2010). It is also revealed by some studies that the SC is mediated in terms of both SCO and SB. Wallace and Chen (2006) argue that SCO impresses personal productivity and safety performance, and the SC mediates the impact on the safety performance of the SCO. The study of Lee and Dalal (2014) suggests that a positive relationship between safety climate and consciousness exists at the personal and organizational level; depending on the effects of intra-organizational conditions, SC and level of consciousness change; and that SB is affected by this change. Thus, we propose that the effect of employees' SCO on their SB was indirect and mediated by SC. Based upon the theoretical framework discussed above, this study developed following hypothesis.

\section{Hypothesis 7: Safety climate mediates the relationship between safety consciousness and safety behavior.}

\section{Methods}

\subsection{Sample}

The survey is designed for administration to employees in Turkey amongst the four main groups of airline employees: operational (aircraft technicians, certifying technicians), safety and quality (auditors, inspectors, and investigators), planning functions (schedule planning, crew planning, and technical support) and operation control (dispatchers and ground operation staff). The surveys were delivered to the willing employees of the target units and were taken back in closed envelopes without specifying their identity information. A total of 250 surveys were distributed and 200 of these surveys filled by employees returned (respons rate \%80). After eliminating cases with missing values, the final sample included 178 employees. Given that only $\% 18$ of the employee was female (\%82 male). The average age of all respondents was 34.2 years $(\mathrm{SD}=7.39)$ with a range from $18-57$ years. Average experience in their current job was 4.79 years $(\mathrm{SD}=4.58)$. Approximately $80 \%$ of them had bachelor's degree. Regarding the marital status of the employees, it was specified that 58 persons (32.6\%) were single and 120 persons $(67.4 \%)$ were married.

\subsection{Data Collection: Survey Instrument}

Our research designed for this study was cross-sectional survey method. Self-administered questionnaires were used in data collection. A Turkish version of the instrument was developed using the back-translation method. All the measures were translated into Turkish language and back translated in English for accuracy. Demographic items were included to allow for descriptive statistics to be performed for an understanding of the sample. Individual ratings of POF were assessed with nine items from Cable and DeRue (2002). A sample item is, "My personal values match my organization's values and culture". Coefficient alpha was 0.89 . Seven items 
were used to measure ratings of SCO taken from Barling et al. (2002). A sample item is "I am well aware of the safety risks involved in my job". Coefficient alpha was 0.85 . Measuring SC perceptions of employees were used Zohar's (2000) SC scale which includes ten items. Coefficient alpha was 0.87. Individual ratings of SB were assessed with 11 items (Hayes, Perander, Smecko, \& Trask, 1998). Coefficient alpha was 0.84. Participants were asked to respond using a five-point Likert scale ranging from (1) strongly disagree to (5) strongly agree.

All data were analyzed with SPSS version 22.0 software and descriptive-inferential method. First of all, Cronbach's alpha coefficients for each of the scales used in this research were computed using reliability analysis to assess the internal consistency of the measuring instruments. Descriptive statistics such as mean scores and standard deviations were computed according to the variables. Pearson product-moment correlation analysis applied in order to check the nature of relationship between the variables and also to identify the level of auto correlations in variables and multicollinearity. The primary data analysis technique employed to test the research hypotheses was a series of regression analyses. A hierarchical multiple regression analysis was also conducted to test possible mediating effect of safety climate. Standardized beta was used for all of regression analyses. Statistical significance was considered for $p$ values less than 0.05 .

\subsection{Exploratory Factor Analysis}

First, EFA was performed to reveal the factor structures of the variables used in the research. KMO coefficient was found to be 0.86 at the level of significance $\mathrm{p}<0,01$ as a result of exploratory factor analysis for the POF scale and it was found that the scale consists of two sub-dimensions called value congruence and needs-demands congruence. These two sub-dimensions explain about $75 \%$ of the total variance. For SCO, the KMO coefficient was found to be 0.85 at the significance level of $\mathrm{p}<0.01$. As a result of the Varimax rotation process, a one-dimensional structure made up with 4 statements which explains about $70 \%$ of the total variance has emerged. The KMO coefficient was 0.85 at the significance level of $p<0.01$ as a result of the EFA which is designed for $\mathrm{SC}$ scale, the mediator variable. As a result of the Varimax rotation process, a structure consisting of two sub-dimensions, explaining about $64 \%$ of the total variance, was obtained. Factor analysis shows that the structure consists of 2 sub-dimensions that were reached in the study of Zohar (2000) and named as supervisor actions and supervisor expectations. As a result of the factor analysis which is applied for the SB which is the dependent variable, the KMO coefficient was 0.75 at the significance level of $p<0.01$. Following the Varimax rotation process, 3 sub-dimensions are described, in which the total variance is explained as about $64 \%$ and is called conscious noncompliance behavior, safety compliance behavior and safety participation behavior. In our research, we applied factor analysis to reveal sub-dimensions of variables, but all each variables are used as a one dimension at the further analyses.

\subsection{Descriptive Statistics and Correlation Analysis}

Table 1 showed the results of the descriptive statistics and Pearson correlation analysis with the Cronbach's alphas for each scale shown in bold and on the diagonal. The results revealed that POF reached a mean 3.73 $(\mathrm{SD}=0.49)$, indicating that a positive fit between organization and employee. Average indicates that there exists a positive POF between the airline and the employee according to employees' perception. It can be concluded that the airline meets the employee's needs and demands at a high level; in return the employees have the necessary capabilities that the airline needs. The mean of the SCO scale is $4.20(\mathrm{SD}=0.47)$, indicating that airline employees are responsible, attentive and disciplined.

Table 1. Descriptive and correlations

\begin{tabular}{llllllll}
\hline Scale & M & SD & Items & 1 & 2 & 3 & 4 \\
\hline POF & 3.73 & 0.49 & 9 & $(0.89)$ & & & \\
SCO & 4.20 & 0.47 & 4 & $0.40^{* *}$ & $(0.85)$ & & \\
SC & 3.98 & 0.51 & 10 & $0.42^{* *}$ & $0.46^{* *}$ & $(0.87)$ & \\
SB & 3.99 & 0.42 & 11 & $0.33^{* *}$ & $0.62^{* *}$ & $0.54^{* *}$ & $(0.84)$ \\
\hline
\end{tabular}

$* \mathrm{p}<0.05, * * \mathrm{p}<0.01$.

The study's mediating variable and descriptive statistics on SC show that the perceptions of the airline employees regarding the safety issues are positive and that the airline management has given importance to the safety aspects of the changing $\mathrm{SC}(\mathrm{M}=3.98$ and $\mathrm{SD}=0.51)$. The mean of the dependent variable (SB) of the study shown in table 1 was 3.99 and the standard deviation was 0.42 . This confirms the compliance with safety rules, and procedures and the level of SB in the airlines high. The Cronbach's alphas which reported earlier confirmed the 
reliability of all measurement scales used for this study. Examination of the correlations between the variables demonstrated that they were highly significant (Table 1). The results concluded that the four variables were significantly correlated with each other. This relationship provided added empirical support for the study model. The presence of a positive mid-level relationship between variables indicates that increases in the level of variables will increase the other variables. Moreover, the correlations among the study variables provided initial support for our hypotheses.

\section{Results}

\subsection{The Effects of POF and SCO on SC and SB}

Multiple regression analysis was used to examine the effects of the study's independent variables (POF and $\mathrm{SCO}$ ) on the mediator variable (SC), and dependent variable (SB). The results of the regression analysis are presented in Table 2.

Table 2. Regression of POF and SCO on SC and SB

\begin{tabular}{llll}
\hline & $\beta$ & $R^{2}$ & $F$ \\
\hline $\mathrm{POF} \rightarrow \mathrm{SC}$ & $0.40^{* *}$ & 0.20 & 6.35 \\
$\mathrm{SCO} \rightarrow \mathrm{SC}$ & $0.44^{* *}$ & 0.23 & 7.52 \\
$\mathrm{POF} \rightarrow \mathrm{SB}$ & $0.27^{* *}$ & 0.17 & 5.23 \\
$\mathrm{SCO} \rightarrow \mathrm{SB}$ & $0.59^{* *}$ & 0.43 & 18.50 \\
\hline
\end{tabular}

$* \mathrm{p}<0.05,{ }^{* * \mathrm{p}}<0.01$.

Regression results show that POF has positive significant effect on $\mathrm{SC}$ at the level of $\mathrm{p}<0.01$ significance $(\beta=0.40)$. However, POF accounts for $20 \%$ of the total variance for $\mathrm{SB}\left(\mathrm{R}^{2}=0.20\right.$ and $\left.\mathrm{F}=6.35\right)$. In addition, the Durbin Watson value (1.985) indicates that autocorrelation is not present between errors and that $\mathrm{R}^{2}$ and $\mathrm{F}$ values are reliable. The statistics support the hypothesis (H1) that POF positively affects the SC and that the increased level of the fit also increases the SC. Based on subjective judgment, the difference between what the organization provide, and the expectations of the employees also determines the level of perception of the fit that is developed for the organization (Judge \& Cable, 1997). Thus, sharing the same or similar values or meeting the demands is one of the components that determine the level of employees' perceptions of SC together with the perceptions of the fit. It is therefore acknowledged that employees with a high sense of fit will be more strongly connected to the rules, policies and procedures established by the organization to ensure safety and to support a positive SC.

Regression analysis shows that POF has positive significant effect on SB ( $\beta=0.27$ and $\left.\mathrm{R}^{2}=0.17\right)$. The model is statistically significant because $\mathrm{F}$ is 5.232 and significance is $\mathrm{p}<0.01(\mathrm{~d}=2.090)$. This suggests that the employee who perceives that the organization has the same or similar values and goals with her/him develops a stronger sense of safety compliance and participation behavior. This supports the study of Sherry (1991), which concluded that POF the safety behavior. While SB refers to compliance with rules, policies and procedures to ensure safety within the organization (Clarke, 2006), POF represents the compatibility that occurs when employees and the organization share similar values and/or meet each other's needs. This situation raises a question: To what extent can an employee with a low level of compliance adapt to the safety rules, policies and procedures of the organization? The conflict between employee values and demands with organizational values and norms will also affect the employee's judgments on all rules and procedures. Weak POF has negative effects on the work outcomes such as job satisfaction, intention to leave work and performance (Kristof, 1996; Bright, 2007; Cable \& Judge, 1996; Vilela et al., 2008). Weak POF has also the potential to explain poor safety behavior.

Findings indicate that $\mathrm{SCO}$ has a positive effect on $\mathrm{SC}\left(\beta=0.44, \mathrm{R}^{2}=0.23\right.$ and $\left.\mathrm{F}=7.52\right)$. The Durbin Watson value (1.960) also supports statistical validity of this effect. Depending on the results, our study supports the studies of Barling et al. (2002) and Lee and Dalal (2014). Thereby, it is shown that personality traits are influential in the formation of SC perceptions and employees, along with other factors, develop safety perceptions based on their level of SCO. Because the level of employees' SCO is a kind of filter in the perception of environmental conditions and in the assessment of risks and threats. It is also noteworthy that the organization formed by employees with a low level of SCO may be insufficient in perceiving the general SC and in evaluating the safety rules and procedures applied by the organization. Therefore, an important finding of this study is that the level of $\mathrm{SC}$ is affected by the employee's SCO. 
The findings of the study support the hypothesis that SCO has a significant effect on SB ( $\beta=0.59, \mathrm{R}^{2}=0.43$ and $\mathrm{F}=18.50$ ). Studies on the subject have shown that employees with a high level of SCO develop more compliance behavior towards safety rules, policies and procedures (Wallace \& Vodanavich, 2003; Clarke \& Robertson, 2005; Inness et al., 2010). The main reason for this compliance behavior is due to the fact that the employee's personality traits such as being organized and compliance guide her/him in following and implementing safety rules in risky environments. In addition, the feeling of self-control and sense of responsibility towards other people ensure her/him not to lose the control even in situations where she/he feels stressful and suppressed. This allows employees with SCO to participate more in the safety-related activities, encourage their colleagues to comply with the rules, and revise safety behaviors by analyzing risks and threats constantly, depending on changing environmental conditions.

\subsection{The Effect of the $S C$ on the $S B$}

In this part of the study, the effect of SC (mediator variable) on SB (dependent variable) is examined by regression analysis.

Table 3. Regression of SC on SB.

\begin{tabular}{llll}
\hline & $\beta$ & $R^{2}$ & $F$ \\
\hline $\mathrm{SC} \rightarrow \mathrm{SB}$ & $0.49^{* *}$ & 0.34 & 12.58 \\
\hline
\end{tabular}

$* \mathrm{p}<0.05,{ }^{* * \mathrm{p}}<0.01$.

The regression analysis given in Table 3 indicates that the SC positively affected the safety behavior $(\beta=0.49$, $\mathrm{R}^{2}=0.34$ and $\mathrm{F}=12.58$ ). Thus, it supports the studies of Clarke (2006), Neal and Griffin (2006), Oliver et al. (2002), Cheyne et al. (1998), Cooper and Philips (2004), Seo (2005) and Hofmann and Stetzer (1996), Petitta, Probst, Barbaranelli and Ghezzi (2017). Employee's perception, attitudes and beliefs about the workplace also affect the behavior of her/his safe work. Employees working in organizations with positive SC develop more compliance behavior in following rules, policies and procedures related to the safety. Because, when employees have the perception that their organizations are concerned about their health and well-being, they also adjust their behaviors according to the rules and policies of their organizations (Neal \& Griffin, 2006). SC perception reflects the collective subjective assessments of all employees. This positive association of perception ensures that possible accidents can be prevented by increasing the effectiveness of safety management systems seen as accident prevention systems and increasing the number of reported unsafe behaviors (Arezes \& Miguel, 2008).

\subsection{Mediation Effect of SC}

In the study, the effect of POF and SCO on SC and SB has been examined by multiple regression analysis. The mediation role of $\mathrm{SC}$ has been analyzed by hierarchical regression analysis. In order to prove mediation effect, it must first have a significant effect on the independent and mediator variable. At the end of the mediation effect test, if there is a decrease or increase in the significant effect of the independent variable on the dependent variable then there is a partial mediation relationship. If there is an insignificant effect, then there is a full mediation relationship (Baron \& Kenny, 1986). The results of analyzes given in Table 1 and Table 2 show that POF and SCO have a significant effect on SC and SB. Moreover, Table 3 shows that SC has a significant effect on SB. The results of multiple regression analysis show that conditions for mediation testing are appropriate. Then hierarchical regression analysis was used to measure the mediating effect of SC. Hierarchical regression analysis results show that the first step effect of POF on SB has lost its effect in the second step, with SC being controlled (Table 4). Therefore, depending on these results, it is seen that the SC has a full mediation role in the relationship between POF and SB.

Table 4. Mediation Effect of SC

\begin{tabular}{lrlll}
\hline & & $\beta$ & $R^{2}$ & $F$ \\
\hline$(\mathrm{POF} \rightarrow \mathrm{SB})$ & Step 1 & $0.27^{* *}$ & 0.17 & 5.23 \\
$(\mathrm{POF} \rightarrow \mathrm{SC} \rightarrow \mathrm{SB})$ & $\mathrm{Step} \mathrm{2}$ & 0.46 & 0.34 & 11.23 \\
\hline
\end{tabular}

$* \mathrm{p}<0.05,{ }^{* *} \mathrm{p}<0.01$. 
Table 5. Mediation effect of SC

\begin{tabular}{lrlll}
\hline & & $\beta$ & $R^{2}$ & $F$ \\
\hline$(\mathrm{SCO} \rightarrow \mathrm{SB})$ & Step 1 & $0.59^{* *}$ & 0.43 & 18.50 \\
$(\mathrm{SCO} \rightarrow \mathrm{SC} \rightarrow \mathrm{SB})$ & Step 2 & $0.29^{* *}$ & 0.50 & 21.14 \\
\hline
\end{tabular}

$* \mathrm{p}<0.05, * * \mathrm{p}<0.01$

In the other mediation relationship, it was observed that effect of the SCO on the SB decreased with the SC being controlled (Table 5). The standardized $\beta$ coefficient value of SCO decreased from 0.59 to 0.29. This decline suggests that the SC has a partial mediating role on SCO. This confirms the hypotheses H4 and H7 about mediating effect.

Study results reveal that POF directly affects SB as well as SC mediated this effect. The employee's POF perception affects behaviors in the context of the level of match with the organization. High match level creates a positive safety climate within the organization, pave the way for the employee to be engaged to safety rules and leads to compliance behaviors. Employees should adjust their behavior depending on the safety sensor. Thus, the factors affecting the SC can be put forward when the accidents are prevented or minimized (Neal \& Griffin, 2006). The findings of the study show POF has a significant impact on SB over the SC than its direct impact on the SC. This situation affects the overall SC, primarily in terms of person and organization, in terms of values, needs and demands. This affects employees' compliance with safety rules, policies and procedures and their participation in safety behaviors. Thus, the organization's precedence on safety and the establishment of rules for providing it are not sufficient for employees to behave in a safe manner. If the employees have a certain level of congruence with the organization in terms of values, needs and demands, then they will support the organization in creating a positive SC.

Findings show that the SC partially mediates the relationship between SCO and SB. This indicates that some of the effects of SCO on SB are shared by the safety SC. The study reaches similar conclusions with and supports the studies of Wallace and Chen (2006) and Lee and Dalal (2014). The employee gets information from the general climate, the culture of organization, the behaviors accepted by his colleagues and management and the rules and procedures that dominate the organization (Zohar, 2000). Therefore, perceptions that depend on the SC prevailing within the organization can be changed independently of the SCO. Because the employee's SCO, the guiding function on SB, is diminished by the intervention of the SC prevailing in the organization, and employees are behaving in a cooperative manner with their SCO and SC (Barling et al., 2002; Clarke, 2010). It may be concluded that only the employees with high level of SCO can demonstrate high levels of SB if a positive SC exists within the organization.

The equation $(\mathrm{Z})=\mathrm{A} * \mathrm{~B} / \sqrt{ }\left(\mathrm{B}^{2} * \mathrm{SEa}^{2}+\mathrm{A}^{2} * \mathrm{SEb}^{2}\right)$ was used to test whether the indirect effect of the independent variable on the dependent variable is statistically significant (Preacher \& Hayes, 2008). Sobel (1982) states that the standard error term can be subtracted from equality because it may have a very small value. A in the equation is the path between the mediator variable and the independent variable, SEa is the standard error of this coefficient, $\mathrm{B}$ is the path between the mediator variable and the dependent variable, and $\mathrm{SEb}$ is the standard error of this coefficient. The value obtained as the result of the calculation is examined in terms of the standard normal distribution suitability at the level of confidence to be determined. Afterwards, it is decided whether the mediating value is statistically significant. Figure 2 and Figure 3 show the Sobel test results for the mediation relationship. The fact that test results at $\mathrm{p}<0.01$ are significant confirms the mediating role of SC statistically.
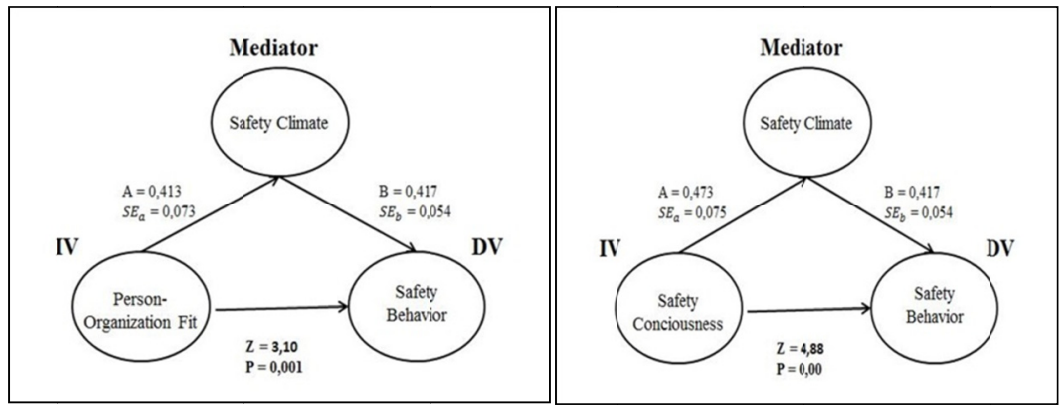

Figure 2. Sobel Tests 


\section{Conclusions}

Aspects of individuals, such as safety values and expectations, interact with facets of safety situations, such as safety incentive systems, safety norms and safety management system to affect the individuals' attitudinal and behavioral safety responses. Our study reveals that congruence between individuals' personalities and safety demands of work are associated with a low likelihood of unsafe behavior in workplace.

Airlines are among the organizations that have safety rules, policies and procedures arranged and implemented at an advanced level due to their high risk working environment. Therefore, it is necessary for employees to strictly comply with such rules, policies and procedures in order to minimize or eliminate the possibility of an accident. In the recruitment processes of airlines, determination of the values and needs of the candidates together with their personality characteristics gain importance in terms of the POF. The high-level fit between the airline and its employees will play a role in their acceptance of airlines' rules, policies and procedures. This is because high-level POF will play a role in filling the gap between the airlines' regulations and the perception of these regulations by employees. Hence, it is recommended that for the candidates in the recruitment process and periodically for current employees, airlines shall measure POF with personality tests to determine values and needs.

Positive applications at airlines such as convincing, awareness rising, and training rather than pressure are crucial to establishing SB. This will also help employees to develop positive SB. Because, forcing employees or punishing their incompatible behaviors can prevent them from accepting the safety behaviors voluntarily. Moreover, concern for the punishment can also prevent employees from reporting some incidents, minor injuries and near-misses. The rewarding of employees who report their mistakes, if necessary, instead of punishment is recommended in terms of establishing a healthy communication between management and employees. Because, if employees have a strong perception that the organization is strongly committed to occupational health and safety, they will accept the rules as useful applications which ensure their health and safety, rather than the obligations to be obeyed.

It is also suggested that airlines should not only be audit-oriented in measuring and developing safety levels, but that employees should consider safety as a priority in their operations, taking into account their health and safety as well as the safety of their infrastructure and facilities. It is proposed to develop a dynamic safety management system that can improve itself only in accordance with the conditions of the day, including the provision of support to specialized independent organizations in the field of operations, compliance with legal boundaries and beyond the suitability of numerical data, SC and employee SB.

\section{Limitations and Future Directions}

In the aspect of POF, the values of the employees, their needs and their congruence to the organization in terms of their expectations from the organization were taken into consideration, instead of the value and needs related to the safety between the employees and the organization. For this reason, it is assumed that the level of POF may also be limited in its effect on SC and SB. It is assessed that it would be more useful to measure the POF with a new scale covering the values and needs related to the safety, instead of measuring through the general criteria.

In our study, we have concluded that SCO has a mediate positive effect on SB. However, the direct impact of SB on the accident remains outside the limits of this study. It would provide a more comprehensive assessment if other personality traits are included in the future studies.

\section{References}

Arezes, P. M., \& Miguel, A. S. (2008). Risk perception and safety behaviour: A study in an occupational environment. Safety Science, 46(6), 900-907. https://doi.org/10.1016/j.ssci.2007.11.008

Barling, J., Loughlin, C., \& Kelloway, E. K. (2002). Development and test of a model linking safety-specific transformational leadership and occupational safety. Journal of AppliedPsychology, 87(3), 488-496. https://doi.org/10.1037/0021-9010.87.3.488

Baron, R. M., \& Kenny, D. A. (1986). The moderator-mediator variable distinction in social psychological research: Conceptual, strategic, and statistical considerations. Journal of Personality and Social Psychology, 51(6), 1173-1182. https://doi.org/10.1037/0022-3514.51.6.1173

Barrick, M. R., \& Mount, M. K. (1991). The big five personality dimensions and job performance: a meta-analysis. Personnel Psychology, 44(1), 1-26. https://doi.org/10.1111/j.1744-6570.1991.tb00688.x

Bright, L. (2007). Does Person-Organization Fit Mediate the Relationship Between Public Service Motivation 
and the Job Performance of Public Employees? Review of Public Personnel Administration, 27(4), 361-379. https://doi.org/10.1177/0734371x07307149

Britton, A. (2014). Safety-Specific Person-Environment Fit: Relation with Safety Behaviors, Job Attitudes, and Strain. (Electronic Thesis or Dissertation). Retrieved from https://etd.ohiolink.edu/

Cable, D. M., \& DeRue, D. S. (2002). The convergent and discriminant validity of subjective fit perceptions. Journal of Applied Psychology, 87(5), 875-884. https://doi.org/10.1037/0021-9010.87.5.875

Cable, D. M., \& Judge, T. A. (1996). Person-Organization Fit, Job Choice Decisions, and Organizational Entry. Organizational Behavior and Human Decision Processes, 67(3), 294-311. https://doi.org/10.1006/obhd.1996.0081

Cheyne, A., Cox, S., Oliver, A., \& Tomás, J. M. (1998). Modelling safety climate in the prediction of levels of safety activity. Work \& Stress, 12(3), 255-271. https://doi.org/10.1080/02678379808256865

Christian, M. S., Bradley, J. C., Wallace, J. C., \& Burke, M. J. (2009). Workplace safety: A meta-analysis of the roles of person and situation factors. Journal of Applied Psychology, 94(5), 1103-1127. https://doi.org/10.1037/a0016172

Clarke, S. (2006). The relationship between safety climate and safety performance: A meta-analytic review. Journal of Occupational Health Psychology, 11(4), 315-327. https://doi.org/10.1037/1076-8998.11.4.315

Clarke, S. (2010). An integrative model of safety climate: Linking psychological climate and work attitudes to individual safety outcomes using meta-analysis. Journal of Occupational and Organizational Psychology, 83(3), 553-578. https://doi.org/10.1348/096317909x452122

Clarke, S., \& Robertson, I. (2005). A meta-analytic review of the Big Five personality factors and accident involvement in occupational and non-occupational settings. Journal of Occupational and Organizational Psychology, 78(3), 355-376. https://doi.org/10.1348/096317905x26183

Cooper, M.D., \& Phillips, R.A. (2004). Exploratory analysis of the safety climate and safety behavior relationship. Journal of Safety Research, 35, 497-512. https://doi.org/10.1016/j.jsr.2004.08.004

Coyle-Shapiro, J., \& Kessler, I. (2000). Consequences Of The Psychological Contract For The Employment Relationship: A Large Scale Survey. Journal of Management Studies, 37(7), 903-930. https://doi.org/10.1111/1467-6486.00210

De Koster, R. B., Stam, D., \& Balk, B. M. (2011). Accidents happen: The influence of safety-specific transformational leadership, safety consciousness, and hazard reducing systems on warehouse accidents. Journal of Operations Management, 29(7-8), 753-765. https://doi.org/10.1016/j.jom.2011.06.005

European Agency for Safety and Health at Work (2017). Retrieved July 11, 2017, from https://osha.europa.eu/en/about-eu-osha/press-room/eu-osha-presents-new-figures-costs-poorworkplace-saf ety-and-health-world

Flin, R., Mearns, K., O'Connor, P., \& Bryden, R. (2000). Measuring safety climate: identifying the common features. Safety Science, 34(1-3), 177-192. http://doi.org/10.1016/S0925-7535(00)00012-6

Fogarty, G. J., \& Buikstra, E. (2008). A test of direct and indirect pathways linking safety climate, psychological health, and unsafe behaviours. International Journal of Applied Aviation Studies, 8(2), 199-210.

Forcier, B. H., Walters, A. E., Brasher, E. E., \& Jones, J. W. (2001). Creating a safer working environment through psychological assessment: A review of a measure of safety consciousness. Journal of Prevention \& Intervention in the Community, 22(1), 53-65. https://doi.org/10.1080/10852350109511211

Hayes, B. E., Perander, J., Smecko, T., \& Trask, J. (1998). Measuring perceptions of workplace safety: Development and validation of the Workplace Safety Scale. Journal of Safety Research, 29(3), 145-161. https://doi.org/10.1016/S0022-4375(98)00011-5

Hofmann, D. A., \& Stetzer, A. (1996). A cross-level investigation of factors influencing unsafe behaviors and accidents. Personnel Psychology, 49(2), 307-339.

Ilkım, N. Ş., \& Derin, N. (2018). Güvenlik iklimi ve iş tatmini ilişkisinde birey-örgüt uyumunun aracı rolü. Ataturk University Journal of Economics \& Administrative Sciences, 32(2), 231-245. Retrieved from http://eds.a.ebscohost.com/eds/pdfviewer/pdfviewer?vid=0\&sid=770f213c-8850-4ec9-aacd0aaeefa81d39\% 40sessionmgr4010

Inness, M., Turner, N., Barling, J., \& Stride, C. B. (2010). Transformational leadership and employee safety 
performance: A within-person, between-jobs design. Journal of Occupational Health Psychology, 15(3), 279-290. https://doi.org/10.1037/a0019380

John, O. P., Naumann, L. P., \& Soto, C. J. (2008). Paradigm shift to the integrative Big Five trait taxonomy: History, measurement, and conceptual issues. In O. P. John, R. W. Robins, \& L. A. Pervin (Eds.), Handbook of Personality: Theory and Research (pp. 114-158). New York, NY, US: Guilford Press.

Judge, T. A., \& Cable, D. M. (1997). Applicant personality, organizational culture, and organization attraction. Personnel Psychology, 50(2), 359-394. http://doi.org/10.1111/j.1744-6570.1997.tb00912

Judge, T. A., Bono, J. E., Ilies, R., \& Gerhardt, M. W. (2002). Personality and leadership: A qualitative and quantitative review. Journal of Applied Psychology, 87(4), 765-780. https://doi.org/10.1037/0021-9010.87.4.765

Kaplan, S., \& Tetrick, L. E. (n.d.). Workplace safety and accidents: An industrial and organizational psychology perspective. APA Handbook of Industrial and Organizational Psychology, Vol 1: Building and Developing the Organization., 455-472. https://doi.org/10.1037/12169-014

Kristof, A. L. (1996). Person-organization fit: An integrative review of its conceptualizations, measurement, and implications. Personnel Psychology, 49(1), 1-49. http://doi.org/10.1111/j.1744-6570.1996.tb01790.x

Kristof-Brown, A. L., Zimmerman, R. D., \& Johnson, E. C. (2005). Consequences of individuals' fit at work: A meta-analysis of person-job, person-organization, person-group, and person-supervisor fit. Personnel Psychology, 58, 281-342. https://dx.doi.org/10.1111/j.1744-6570.2005.00672.x

Laurence, D. (2005). Safety rules and regulations on mine sites - the problem and a solution. Journal of Safety Research, 36(1), 39-50. https://doi.org/10.1016/j.jsr.2004.11.004

Lee, S., \& Dalal, R. S. (2016). Climate as situational strength: Safety climate strength as a cross-level moderator of the relationship between conscientiousness and safety behaviour. European Journal of Work and Organizational Psychology, 25(1), 120-132. https://doi.org/10.1080/1359432X.2014.987231

Liao, P. C., Lei, G., Xue, J., \& Fang, D. (2015). Influence of Person-Organizational Fit on Construction Safety Climate. Journal of Management in Engineering, 31(4), 04014049. https://doi.org/10.1061/(asce)me.1943-5479.0000257

Maierhofer, N. I., Griffin, M. A., \& Sheehan, M. (2000). Linking manager values and behavior with employee values and behavior: a study of values and safety in the hairdressing industry. Journal of Occupational Health Psychology, 5(4), 417-427. https://doi.org/10.1037/1076-8998.5.4.417

Mearns, K. J., \& Flin, R. (1999). Assessing the state of organizational safety-culture or climate? Current Psychology, 18(1), 5-17. https://doi.org/10.1007/s12144-999-1013-3

Meyer, R. D., Dalal, R. S., \& Bonaccio, S. (2009). A meta-analytic investigation into the moderating effects of situational strength on the conscientiousness-performance relationship. Journal of Organizational Behavior, 30(8), 1077-1102. https://doi.org/10.1002/job.786

Neal, A., \& Griffin, M. A. (2006). A study of the lagged relationships among safety climate, safety motivation, safety behavior, and accidents at the individual and group levels. Journal of Applied Psychology, 91(4), 946-953. https://doi.org/10.1037/0021-9010.91.4.946

Neal, A., Griffin, M. A., \& Hart, P. M. (2000). The impact of organizational climate on safety climate and individual behavior. Safety Science, 34(1-3), 99-109. https://doi.org/10.1016/S0925-7535(00)00008-4

Oliver, A., Cheyne, A., Tomas, J.M., \& Cox, S., (2002). The effects of organizational and individual factors on occupational accidents. Journal of Occupational and Organizational Psychology, 75, 473-488. http://doi.org/10.1348/096317902321119691

Park, H. I., Monnot, M. J., Jacob, A. C., \& Wagner, S. H. (2011). Moderators of the relationship between person-job fit and subjective well-being among asian employees. International Journal of Stress Management, 18(1), 67-87. https://doi.org/10.1037/a0021854

Petitta, L., Probst, T. M., Barbaranelli, C., \& Ghezzi, V. (2017). Disentangling the roles of safety climate and safety culture: Multi-level effects on the relationship between supervisor enforcement and safety compliance. Accident Analysis \& Prevention, 99, 77-89. https://doi.org/10.1016/j.aap.2016.11.012

Postlethwaite, B., Robbins, S., Rickerson, J., \& McKinniss, T. (2009). The moderation of conscientiousness by cognitive ability when predicting workplace safety behavior. Personality and Individual Differences, 47(7), 
711-716. https://doi.org/10.1016/j.paid.2009.06.008

Preacher, K. J., \& Hayes, A. F. (2008). Asymptotic and resampling strategies for assessing and comparing indirect effects in multiple mediator models. Behavior Research Methods, 40(3), 879-891. https://doi.org/10.3758/BRM.40.3.879

Reason, J. T. (1998). Achieving a safe culture: theory and practice. Work \& Stress, 12(3), 293-306. https://doi.org/10.1080/02678379808256868

Schneider, B. (1987). The people make the place. Personnel Psychology, 40(3), 437-453. https://doi.org/10.1111/j.1744-6570.1987.tb00609.x

Seo, D. C. (2005). An explicative model of unsafe work behavior. Safety Science, 43(3), 187-211. https://doi.org/10.1016/j.ssci.2005.05.001

Sherry, P. (1991). Person-environment fit and accident prediction. Journal of Business and Psychology, 5(3), 411-416. https://doi.org/10.1007/BF01017711

Sobel, M. E. (1982). Asymptotic confidence intervals for indirect effects in structural equation models. Sociological Methodology, 13, 290-312. https://doi.org/10.2307/270723

Stewart, G. L. (1999). Trait bandwidth and stages of job performance: Assessing differential effects for conscientiousness and its subtraits. Journal of Applied Psychology, 84(6), 959-968. https://doi.org/10.1037/0021-9010.84.6.959

Sutherland, V. J., \& Cooper, C. L. (1991). Personality, stress and accident involvement in the offshore oil and gas industry. Personality and Individual Differences, 12(2), https://doi.org/10.1016/0191-8869(91)90103-I

Tomas, J. M., Melia, J. L., \& Oliver, A. (1999). A cross-validation of a structural equation model of accidents: Organizational and psychological variables as predictors of work safety. Work \& Stress, 13(1), 49-58. https://doi.org/10.1080/026783799296183

Vilela, B. B., Gonzalez, J. A. V., \& Ferrin, P. F. (2008). Person-organization fit, OCB and performance appraisal: Evidence from matched supervisor-salesperson data set in a Spanish context. Industrial Marketing Management, 37(8), 1005-1019. https://doi.org/10.1016/j.indmarman.2007.11.004

Wallace, C., \& Chen, G. (2006). A multilevel integration of personality, climate, self- regulation, and performance. Personnel Psychology, 59(3), 529-557. https://doi.org/10.1111/j.1744-6570.2006.00046.x

Wallace, J. C., \& Vodanovich, S. J. (2003). Workplace safety performance: conscientiousness, cognitive failure, and their interaction. Journal of Occupational Health Psychology, 8(4), 316-327. https://doi.org/10.1037/1076-8998.8.4.316

Zohar, D. (1980). Safety climate in industrial organizations: theoretical and applied implications. The Journal of Applied Psychology, 65(1), 96-102. https://doi.org/10.1037/0021-9010.65.1.96

Zohar, D. (2000). A group-level model of safety climate: Testing the effect of group climate on microaccidents in manufacturing jobs. Journal of Applied Psychology, 85, 587-596. https://doi.org/10.1037/0021-9010.85.4.587

Zohar, D. (2013). Safety climate: Conceptualization, measurement, and improvement. In Schneider, B., \& Barbera, K.M. (Eds.). The Oxford Handbook of Organizational Climate and Culture. (pp. 317- 334). New York: Oxford University Press.

\section{Copyrights}

Copyright for this article is retained by the author(s), with first publication rights granted to the journal.

This is an open-access article distributed under the terms and conditions of the Creative Commons Attribution license (http://creativecommons.org/licenses/by/4.0/). 